\title{
Marko Perčić
}

E-mail: mpercic@riteh.hr

Tehnički fakultet Sveučilišta u Rijeci, Vukovarska 58, 51000 Rijeka

\section{Obnovljivi izvori energije u kontekstu morske tehnologije - sadašnjost i budući trendovi}

\begin{abstract}
Sažetak
Energija mora kao jedan od najmanje iskorištenih obnovljivih izvora energije zahtjeva više pažnje u znanstvenom i stručnom smislu. Ovaj rad daje sažeti pregled potencijala energije mora, te različitih vrsta i principa rada različitih uređaja za iskorištavanje energije valova u kojoj je sadržana najveća količina neiskorištenog potencijala energije mora.
\end{abstract}

Ključne riječi: morska tehnologija, obnovljivi izvori energije, energija valova, konverzija energije

\section{Uvod}

Svjedoci smo globalnog trenda u povećanju korištenja obnovljivih izvora energije. Potreba za tim povećanjem se javila iz različitih ekonomskih, ekoloških, geopolitičkih i drugih razloga. Resursi energije iz prirodnih izvora zahtijevaju dublje razumijevanje različitih prirodnih fenomena ako npr. Sunčevog zračenja, strujanja zračnih struja, gibanje vodenih masa, itd. Ovaj rad daje prikaz tehnoloških trendova za iskorištavanje obnovljivih izvora energije u kontekstu morske tehnologije, tj. same energije mora. Energija mora uz solarnu energiju, hidroenergiju, geotermalnu energiju i energiju vjetra predstavlja veliki neiskorišteni potencijal. Slabija iskorištenost energije mora u odnosu na druge, možda konvencionalnije obnovljive izvore energije, ima razlog u tome što je tehnologija potrebna da bi se energija mora iskoristila kompleksna u svakom svom aspektu; od planiranja, prikupljanja podataka o morskim strujama, valovima, itd., izrade u nekim slučajevima kolosalnih uređaja, te njihova eksploatacija u najtežim uvjetima na pučini mora, itd. Zbog tih poteškoća ovaj obnovljivi izvor nije imao toliko nagli razvoj kao npr. sunčeva i energija vjetra u zadnjih nekoliko desetljeća. Upravo zbog toga energija mora u zadnje vrijeme uživa sve veći interes znanstvene zajednice i inženjerske struke, što je dokaz kako multidisciplinarnost drži ključ rješenju ovakvih tehničkih problema. 
Ideja za korištenjem energije valova nije nova, najranije indikacije korištenja su pronađene u Kini u 13. stoljeću gdje su valovi pokretali mlinove. Prvi patent je objavljen tek 1799. [1] u Francuskoj, također u Francuskoj je 1910. Praceique-Bochaux jedan od prvih primijenio energiju valova kako bi napajao električnom energijom svoj dom u Royan-u. Japanac Yoshio Masuda je 1940. razvijao koncept oscilirajućeg vodenog stupca OWC (Oscillating Water Column). Tokom 1970.-ih godina ponukani naftnom krizom Stephen Salter, Kjell Budal, te Michael E. McCormick su prvi na znanstveni način počeli istraživati ovu zanimljivu tehnologiju.

\section{Globalni resursi energije mora}

More zauzima 71\% Zemljine površine. Ogromna količina energije [2] (kinetičke i toplinske) u vodenoj masi se može razdijeliti na sljedeće podvrste:

- Plime i oseke: $>300 \mathrm{TWh} / \mathrm{a}$

- Strujanja: > $800 \mathrm{TWh} / \mathrm{a}$

- Osmoze: $2000 \mathrm{TWh} / \mathrm{a}$

- Toplinske energije: $10000 \mathrm{TWh} / \mathrm{a}$

- Energije valova: 8000 - $80000 \mathrm{TWh} / \mathrm{a}$

Prema prethodno rečenom vidljivo je da najveći (neiskorišteni) potencijal leži u energiji valova, te će taj dio energetskog spektra mora biti obrađen u ovome radu. Relativno široki raspon u maksimalnoj energiji valova leži u tome što energija valova ovisi o lokaciji na Zemlji, tj. o kojem se moru radi, jasno je da neće biti ista kinetička energija na tvorenom Atlantskom ili Tihom oceanu u odnosu na Jadransko more koje ima zanemarivu količinu energije valova.

Osim velikog potencijala energija valova je također pouzdanija u energetskom smislu zbog veće gustoće energije $\left(2-3 \mathrm{~kW} / \mathrm{m}^{2}\right)$ u odnosu na energiju vjetra $(0,4-0,6$ $\left.\mathrm{kW} / \mathrm{m}^{2}\right)$ i solarnu energiju $\left(0,1-0,2 \mathrm{~kW} / \mathrm{m}^{2}\right)$ [2]. Osim toga neke od prednosti energije valova su također: valovi mogu prijeći velike udaljenosti sa malim gubitkom energije [1, $3]$, te pretvarači energije valova mogu generirati energiju do $90 \%$ pogonskog vremena u odnosu na $20 \%$ za solarnu i $30 \%$ za energiju vjetra [3, 4]. Negativne strane, tj. poteškoće pri pretvorbi ove vrste energije su: problem pretvorbe velikih frekventnih varijacija u energiji valova u iskoristivi ,glatki“" napon od $50 \mathrm{~Hz}$ za iskorištenje u električnoj mreži, uslijed promjenjivih smjerova strujanja i valova uređaji moraju izdržati ekstremne uvjete rada što uzrokuje velike konstrukcijske izazove te otežava operacije održavanja na udaljenim pučinskim dijelovima, te naravno problem predstavlja i financiranje koje je kod ove tehnologije velikog raspona uslijed velikih konstrukcijskih, organizacijskih i logističkih troškova, također treba uzeti u obzir i „natjecanje“ ove tehnologije sa daleko razvijenijim i zrelijim tehnologijama kao što su vjetro i solarna energija.

Kao predispozicija za osnivanje sustava za korištenje energije valova potrebno je izraditi bazu znanja o energetskim mogućnostima pojedine lokacije na svijetu. Različiti radovi predstavljaju raspodjelu energije valova i predviđanje moguće iskoristive 
energije, između stalih [5 -9], gdje su najkvalitetniji podaci dobiveni visoko preciznom satelitskom altimetrijom i desetogodišnjim podacima mjernih plutača što je rezultiralo tzv. atlasom valova prikazanim na slici 1 .

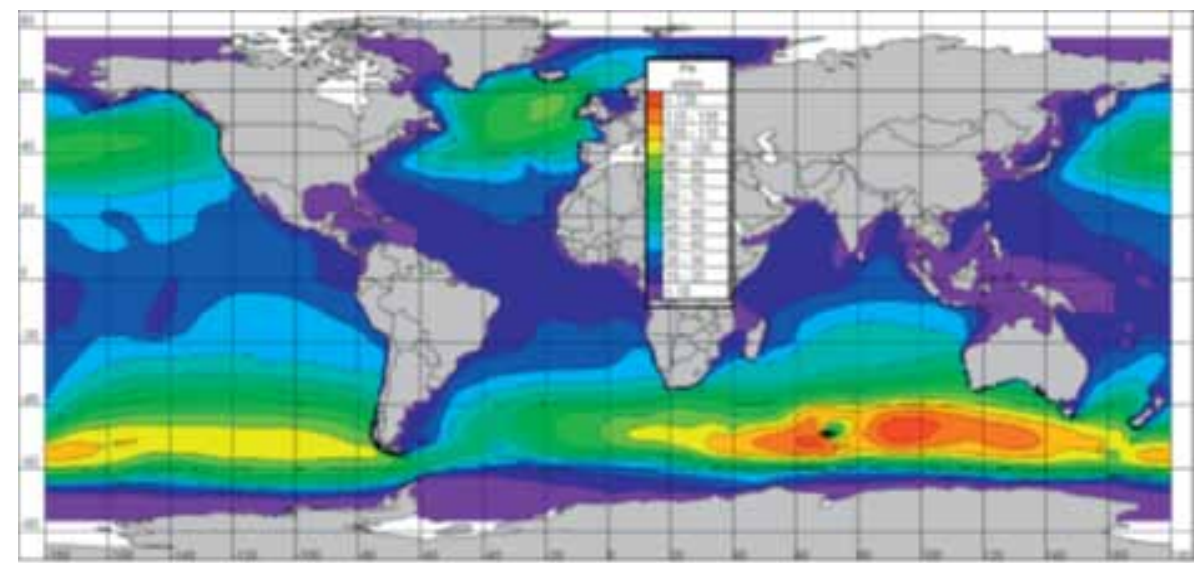

Slika 1: Globalna procjena prosječne snage energije valova u desetogodišnjem periodu [8].

Energija valova je najčešće opisana u smislu snage po metru visine vala $P_{v}(1)$ ili $\mathrm{u}$ formi snage po metru širine vala $\mathrm{P}_{\breve{s}}(2)$ :

$$
\begin{gathered}
P_{v}=\frac{1}{8 \pi} \rho g^{2} A^{2} T\left[\frac{k W}{m}\right] \\
P_{\check{s}}=\frac{1}{32 \pi} \rho g^{2} H^{2} T\left[\frac{k W}{m}\right]
\end{gathered}
$$

\section{Pretvorba energije valova}

Veliki broj različitih vrsta uređaja za pretvorbu energiju valova (naziv u literaturi WEC: Wave Energy Converter) u primarno električnu energiju je razvijeno do danas. Svi ti uređaji se mogu grupirati u tri skupine, ovisno o: lokaciji za eksploataciju, veličini uređaja, i principu rada.

\subsection{Lokacija eksploatacije}

Lokacija eksploatacije pojedine vrste WEC uređaja se određuje prema udaljenosti o obale: obalni, priobalni i pučinski.

- Obalni WEC uređaji su postavljeni na samoj obali, mogu biti iznad razine mora, integrirani u lukobrane, brane ili postavljeni na litice. Prednost ovih 
uređaja je njihovo lako održavanje zbog dostupnosti sa obale. Ne trebaju sustave za sidrenje niti duge vodiče za spajanje sa električnom mrežom. Nedostatak ove lokacije je to što valovi imaju manju energiju zbog interakcije sa morskim dnom, te je također problem prikladna lokacija i ekološki problemi jer je obalna topografija promijenjena s ovim uređajima. [10]

- Priobalni WEC uređaji se postavljaju na unutar nekoliko stotina metara udaljenosti od obale na srednjim dubinama od 10-25 m. Uglavnom leže na dnu te se tako izbjegavaju sustavi sidrenja, dok u drugim slučajevima mogu biti i plutajuće strukture. [10]

- Pučinski WEC uređaji su postavljeni u dubokom moru (>40m), daleko od obale, te postavljeni kao plutajuće ili uronjene strukture u oba slučaja usidrene za morsko dno. Zbog svog povoljnog položaja mogu iskoristiti veliku energiju, ali također zbog svoje lokacije pouzdanost konstrukcije je veliki problem zbog ekstremnih uvjeta eksploatacije te je također i održavanje otežano u uvjetima tvorenog mora. Osim toga ovi uređaji moraju biti povezani skupim podmorskim kabelima za elektroenergetsku mrežu. [10]

\subsection{Veličina uređaja}

Podjela WEC uređaja prema veličini i valnoj karakteristici (smjer nastrujavanja valova na uređaj) $[10,11]$ se vrši na atenuatore, točkaste apsorbere (point apsorbers) i na terminatore, Slika 2.

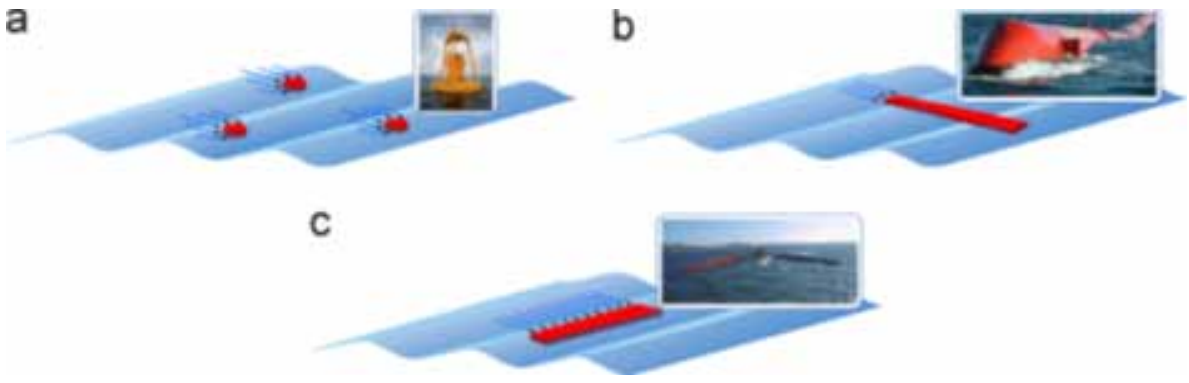

Slika 2: Vrste WEC uređaja prema veličini: a) točkasti asorber (point apsorber), b) atenuator (Pelamis), i c) terminator (Wave Dragon).

- Atenuatori su WEC uređaji koji imaju dugačku strukturu uspoređeno sa valnom duljinom, te se postavljaju paralelno sa smjerom strujanja valova. $\mathrm{U}$ suštini oni umanjuju (attenuate - eng. Umanjiti, razblažiti) amplitudu vala. Ovi uređaji su sastavljeni od niza cilindričnih sekcija povezanih međusobno fleksibilnim zglobovima koji omogućavaju rotaciju pojedinih sekcija. Tipični primjer ove vrste uređaja je Pelamis konverter učina 750 kW (www. pelamiswave.com). 
- Točkasti apsorberi u odnosu na valnu duljinu su znatno manji uređaji. Za razliku od drugih uređaja točkasti apsorberi sakupljaju energiju iz svih smjerova svog gibanja. Pretvorba ljuljanja, translacijskog i rotacijskog gibanja u električnu energiju se vrši preko mehaničkih prijenosnika u rotacijsko ili oscilatorno gibanje generatora, tipična snaga pojedinog uređaja ovog tipa je $150 \mathrm{~kW}$.

- Terminatori su uređaji koji su u principu slični atenuatorima po pitanju veličine. Ovi uređaji su postavljeni okomito na smjer strujanja valova te svojim djelovanjem zaustavljaju valove (terminate - eng. okončati, zaustaviti).

\subsection{Princip rada}

Kao što je prethodno spomenuto podjela WEC uređaja prema principu rada je sljedeća [10]:

- Razlika tlakova: Uređaji u ovoj skupini se mogu podijeliti u dvije podkategorije: pretvaraču na principu Arhimedovog efekta, i uređaji koji rade na principu oscilirajućeg stupca vode (OWC - Oscillating Water Column). Uređaji koji rade na principu Arhimedovog efekta su u principu podvodni točkasti apsorberi postavljeni u priobalnom području i usidreni za dno. Koriste razliku tlakova koja se stvara kada brjegovi i dolovi valova nastrujavaju preko uređaja, te tlak vode komprimira zrak unutar uređaja te ga pomiče na dolje, kada je dol vala iznad uređaja, tlak vode pada te se uređaj pomiče na gore. Tipičan primjer ove vrste uređaja je AWS Archimedes Wave Swing učina $250 \mathrm{~kW}$ (www.awsocean.com) [12]. OWC uređaji su uglavnom postavljeni na obali ili uz obalu, te funkcioniraju na istom principu kao i prethodno spomenuti uređaji. Polu potopljena komora otvorena na dnu vrši oscilirajuće kretnje po utjecajem valova, gdje se razina vode unutra mijenja sa nastrujavanjem valova te zrak u komori struji kroz turbinu koja rotira uvijek u istom smjeru bez obzira na smjer strujanja zraka. Primjeri ovog principa su Limpet $500 \mathrm{~kW}$ i Oceanlix $500 \mathrm{~kW}$.

- Plutajuće strukture, kako im ime kaže, ovi uređaji su bazirani na plutajućem tijelu koje se pomiče valovima. Korisno oscilatorno gibanje tijela može biti vertikalno, horizontalno, bočno, rotacijsko, ili kombinacija. Primjeri su Searaser WEC i Wavestar uređaji. (www.wavestarenergy.com)

- Nadvišeni (Overtopping) uređaji: kod ovih uređaja voda struji na način da ide preko strukture, $\mathrm{tj}$. rezervoara iznad površine mora, te ispuštanje iste vode natrag na razinu mora kroz turbine, tako iskorištavajući potencijalnu energiju. Primjeri ovog principa je Wave Dragon 4-10 MW [13].

- Udarni (Impact) uređaji koji su artiklurane ili fleksibilne strukture postavljene okomito na smjer nastrujavanja valova. Na taj način pomična 
ploča se giba naprijed-nazad zbog udara valova. Primjer ovog tipa uređaja je Aquamarine Power Oyster 800 kW (www.aquamarinepower.com).

Vidljivo je da postoji veliki raspon različitih uređaja ovisno o njihovom principu rada. Ovdje su prikazane samo glavne skupine dok u praksi postoje desetci različitih uređaja koji rade i na kombinacijama prethodno spomenutih radnih principa. Ipak specijalizirane tvrtke najviše proizvode WEC uređaje na principu točkastog apsorbera (point apsorber) kao što je vidljivo na slici 3.
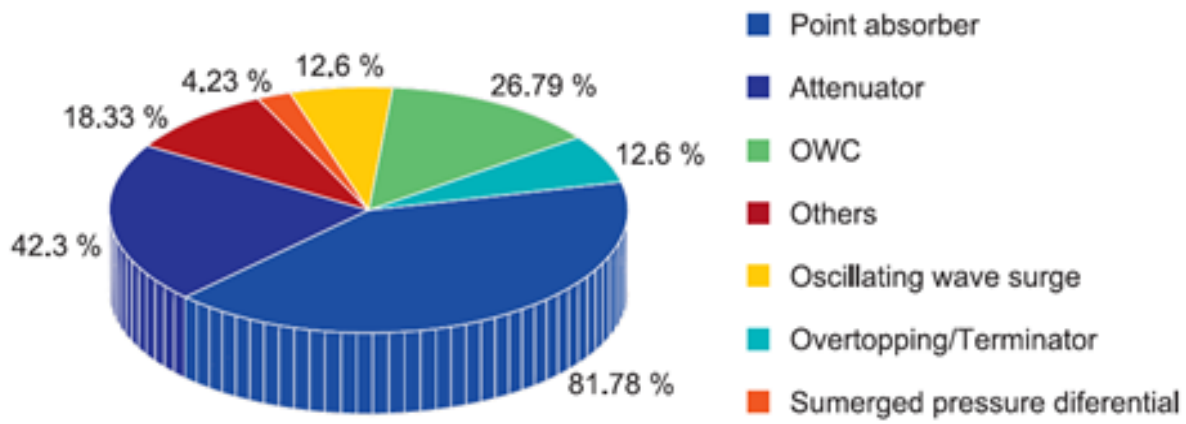

Slika 3: Udio WEC uređaja u proizvodnji i razvoju prema principu rada.

Shematski prikaz prethodno opisanih principa rada dan je na slici 4.:

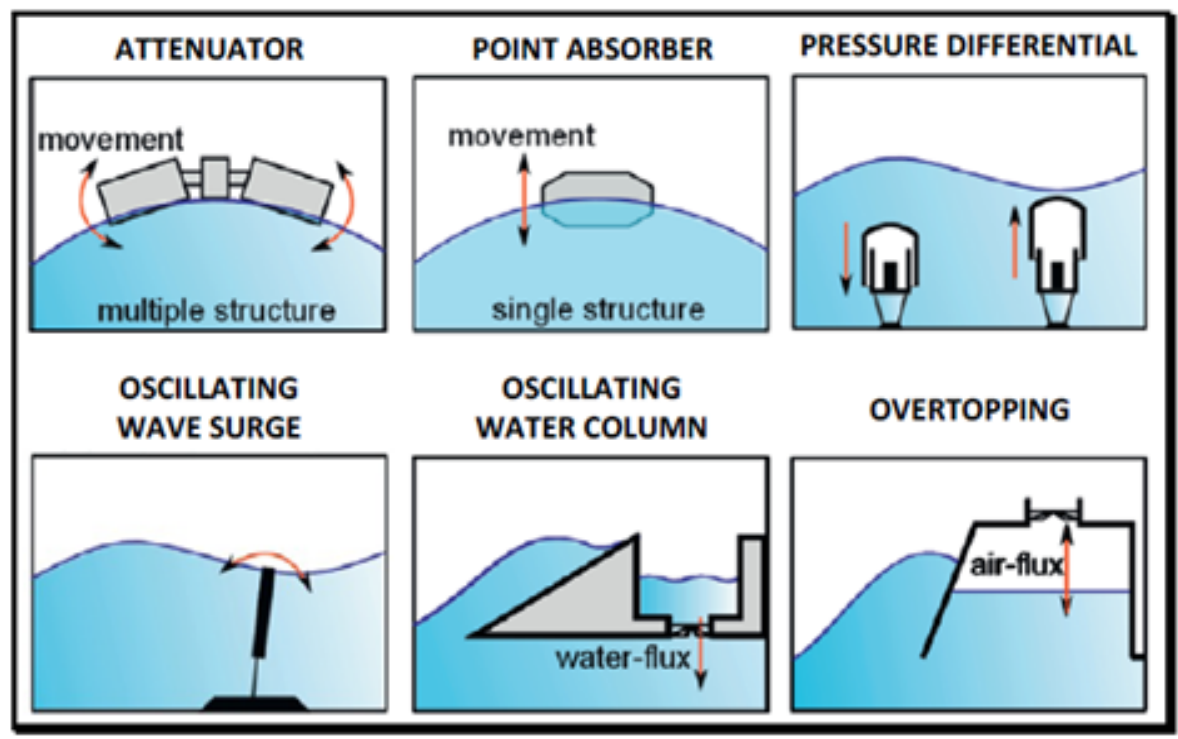

Slika 4: Principi rada WEC uređaja za pretvorbu energije valova [10]. 
Tvrtke $\mathrm{i}$ istraživačke ustanove kontinuirano rade na novim inovacijama kako bi se energija mora što efikasnije iskorištavala, u svijetu u tome prednjače jasno zemlje koje imaju velika ulaganja u istraživanje i razvoj (R\&D) te veliki broj tvrtki u tom području, što je prikazano na karti na slici 4.

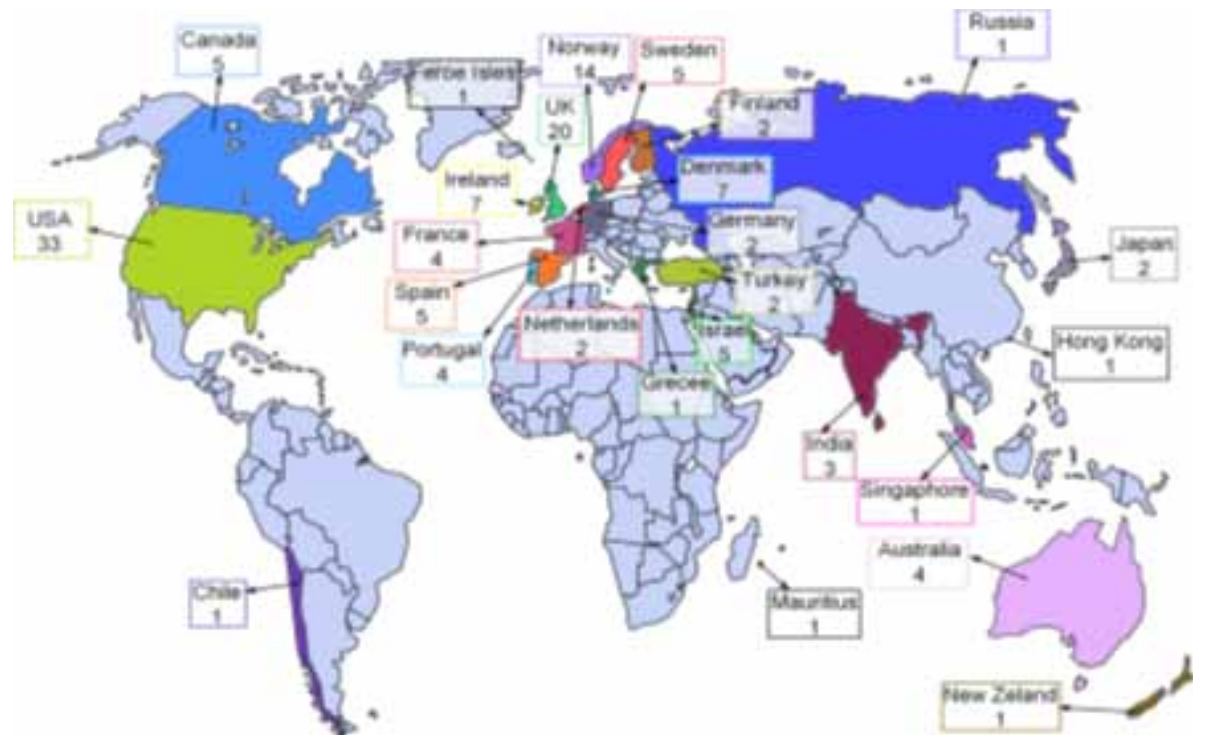

Slika 4: Inovacije u području WEC uređaja po zemljama. (izvor: www.emec.org.uk).

\section{Zaključak}

Energija mora je još uvijek velikim dijelom neiskorišteni resurs obnovljivih izvora energije koji su toliko potrebni u naše vrijeme, a u budućnosti još i više. Velika kompleksnost problema na inženjerskom i znanstvenom nivou, te sama količina energije za koju znamo da je neiskorištena, je dovoljan izazov za buduće istraživače i konstruktore. Ovaj problem je moguće riješiti samo sinergijom različitih područja struke i znanosti. U posljednje vrijeme (zadnjih 15-ak) godina došlo je do velikog broja novih testnih postrojenja za iskorištavanje energije valova i mora općenito. Ovaj rad je mali sažeti prikaz ovog velikog područja istraživanja te se zainteresirani čitatelj svesrdno ohrabruje za daljnje istraživanje ove zanimljive teme. 


\section{Literatura}

1. CLEMENT, MCCULLENP, FALCAO A, FIORENTINO A, GARDNER F, HAMMARLUND K, et al. Wave energy in Europe:currentstatus and perspectives. Renewable and Sustainable Energy Reviews 2002; 6:405-31.

2. IEA OES Annual Report 2014, https://report2014.ocean-energy-systems.org/, pristupljeno 12.10.2015.

3. DREW B, PLUMMER A, SAHINKAYA M. A review of wave energy converter technology. Proceedings of the Institution of Mechanical Engineers, PartA: Journal of Power and Energy 2009; 223:887-902. [4] PELC R, FUJITA R M. Renewable energy from the ocean, .Marine Policy 2002; 26:471-9.

4. CORNETT V., A global wave energy resource assessment., International offshore and polar engineering conference (ISOPE), vol. 1, 2008. p.318-26.

5. BARSTOW S, MORK G, MOLLISON D, CRUZ J. The wave energy resource, Ocean Wave energy, vol. 1.Berlin Heidelberg:Springer; 2008. p.93-132.

6. BARSTOW S, MORK G, LONSETH L, MATHISEN J. Worldwaves wave energy resource assessments from the deep ocean to the coast., European wave and tidal energy conference, vol. 1, 2009. p.149-59.

7. ARINAGA R, CHEUNG K. Atlas of global wave energy from 10 years of reanalysis and hindcastdata, Renewable Energy 2012; 39:49-64.

8. REGUERO B,VIDAL C, MENENDEZ M, MENDEZ F, MINGUEZ R, LOSADA I, Evaluation of global wave energy resource, OCEANS, 2011. p.1-7.

9. CZECH B, BAUER P. Wave energy converter concepts:design challenges and classification, Industrial Electronics Magazine, IEEE 2012; 6:4-16.

10. LAGOUN M, BENALIA A, BENBOUZID M, Ocean wave converters:state of the art and current status, International energy conference and exhibition (EnergyCon), 2010. p.636-41.

11. POLINDER H, DAMEN M, GARDNER F, Design, modelling and test results of the AWS PM linear generator, European Transactions on Electrical Power, 2005; 15:245-56.

12. KOFOED J P, FRIGAARD P, FRIIS-MADSEN E, SORENSEN H C ,Prototype testing of the wave energy converter Wave Dragon, Renewable Energy, 2006; 31(2): 181-9. 
Marko Perčić

\title{
Renewable Energy Sources in the Context of Marine Technology - Present and Future Trends
}

\begin{abstract}
Marine energy as one of the least utilized renewable energy resource requires more attention in the scientific and professional sense. This paper summarizes the energy potential, different types and operating principles of devices for the exploitation of wave energy in which the largest amount of untapped energy potential still resides.
\end{abstract}

Keywords: marine technology, renewable energy sources, wave energy, energy conversion 
